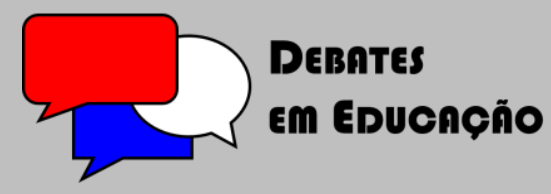

ISSN Eletrônico: 2175-6600

Vol. 10 | №. 20 | Jan./Abr. | Ano 2018

\section{Rosemeire Reis}

Universidade Federal de Alagoas (UFAL)

reisroseufal@gmail.com

\section{Camila Aloisio Alves}

Faculdade de Medicina de Petrópolis (FMP) camila.aloisioalves@gmail.com

\section{Deise Juliana Francisco}

Universidade Federal de Alagoas (UFAL) deisej@gmail.com

\section{EDITORIAL}

\section{v. 10 , n. $20(2018)$}

É com prazer que apresentamos a primeira edição da Revista Debates em Educação do ano de 2018, especificamente v. 10, n. 20 (2018). Ela é composta pelo Dossiê "Educação e juventudes: contribuições da pesquisa biográfica na sociedade contemporânea", organizado por Rosemeire Reis e Camila Aloísio Alves. Na sequência, apresentamos os artigos de fluxo contínuo, resenhas e resumos de dissertações.

Nesta edição, apresentaremos os artigos franceses em duas versões (francês e português). Agradecemos o apoio da Fundação de Amparo à Pesquisa do Estado de Alagoas (FAPEAL), através do Edital № 5/2016 - apoio à editoração e publicação de periódicos científicos - que viabilizou a tradução dos artigos. Da mesma forma, agradecemos as tradutoras Maria Stela Torres Barros Lameiras e Rosária Cristina Costa Ribeiro pelo apoio na tradução de quatro artigos desta edição e a Camila Aloísio Alves e Rosemeire Reis pela tradução de um artigo. 


\section{DOSSIÊ TEMÁTICO “EDUCAÇÃO E JUVENTUDES: CONTRIBUIÇÕES DA PESQUISA BIOGRÁFICA NA SOCIEDADE CONTEMPORÂNEA"}

É com imenso prazer que veiculamos a publicação desse dossiê que focaliza a pesquisa biográfica e suas contribuições para os estudos sobre/com as juventudes na sociedade contemporânea. Ele é fruto de um diálogo profícuo entre o trabalho do grupo de pesquisa “Juventudes, Culturas e Formação" (PPGE/UFAL/CNPq) e o Collège international de recherche biographique en éducation (CIRBE, EXPERICE, Paris 13 Sorbonne Paris Cité).

Esse encontro pressupõe o diálogo entre estudos que focalizam as juventudes em contextos educativos escolares e não escolares, como sujeitos plurais, inseridos nos contextos sócio históricos, com suas condições e os diferentes modos de expressar suas culturas e, a pesquisa biográfica, que estuda como os indivíduos se tornam sujeitos, concomitantemente singulares e sociais. Esses enfoques articulam-se e nutrem-se, além de permitirem o questionamento das concepções predominantes da juventude como grupo homogêneo e pré-concebido a partir de determinadas representações, valorizando os espaços de diálogo e de escuta que engendram processos de reflexão co-partilhados, de construção e/ou reconstrução de narrativas com produção de sentidos e que podem contribuir para fazer emergir o « poder de agir » daqueles que dele participam.

Temas como a construção identitária, gênero, sexualidade, formação educacional, entrada no mercado de trabalho, religiosidade, delinquência, relação com o aprender de modo geral e na escola, entre outros, atravessam a vida destes sujeitos nas sociedades contemporâneas ocidentais. Tornar-se jovem é um exercício que se inscreve nos contextos sociais, educacionais, históricos e culturais, nos quais os indivíduos estão inseridos. Tratase de um fenômeno que exige um olhar e uma abordagem abertos para que se possa captar, entender e compreender suas diferentes facetas. A temática da juventude é, com isso, repleta de perspectivas a serem exploradas através das pesquisas em ciências humanas e sociais.

Nos últimos anos, diversos estudos e projetos têm mostrado que a abertura, promoção e institucionalização de espaços de diálogo e de expressão dos/as jovens nas sociedades contemporâneas são de fundamental importância para a implicação dos/as mesmos/as nos processos educativos críticos. Colocamos em relevo as iniciativas de pesquisa que consideram o/a jovem como ator social e portador/a de histórias singulares que ajudam na compreensão da construção de seus processos identitários em diálogo com suas inscrições sócio históricas. 
Contudo, tais iniciativas vêm-se limitadas diante da emergência de propostas e políticas públicas brasileiras atuais que, em nome de considerar as necessidades dos/as jovens, propõem percursos formativos menos qualificados para aqueles que precisam entrar rapidamente no mundo do trabalho. Um exemplo desse processo foi a aprovação da lei que reformula o ensino médio no Brasil (Lei no 13.415, de 16 de fevereiro de 2017).

A fim de endossar uma postura problematizadora no campo da educação diante do cenário contemporâneo e com vias a contribuir para fomentar a perspectiva que considera o/a jovem como sujeito singular e social, o presente dossiê foi organizado e elaborado segundo dois objetivos, a saber:

- Socializar as contribuições de estudos internacionais e nacionais que abordaram as temáticas juventudes e educação e que foram realizados no escopo da Pesquisa Biográfica em Educação;

- Colocar em debate as possibilidades e limites dos estudos desenvolvidos no escopo da Pesquisa Biográfica em Educação no contexto da sociedade contemporânea, onde a necessidade de espaços de diálogo e de reconhecimento dos modos de expressão dos(as) jovens em diferentes dimensões se mostram crescentes, sobretudo nas práticas educativas escolares.

A escolha pela abordagem epistemológica e metodológica da Pesquisa Biográfica em Educação norteia os artigos que compõem este dossiê visando salientar que a compreensão da experiência de tornar-se jovem precisa considerar, como evoca Christine Delory-Momberger (2014), os processos de gênese e de devir dos indivíduos no seio do espaço social, colocando em evidência como eles dão forma à suas experiências, como fazem significar as situações e os acontecimentos de suas existências.

Através da Pesquisa Biográfica em Educação torna-se oportuno interrogarmos os espaços existentes, e aqueles que precisam ser explorados, onde a narrativa dos/as jovens pode se expressar e dar forma às histórias de vida vividas.

Assim, o dossiê contará com a entrevista da professora doutora Christine DeloryMomberger, Présidente do Collège international de recherche biographique en éducation (CIRBE), Diretora da revista internacional de Pesquisa Biográfica em Educação « Le sujet dans la Cité » em parceria com a professora Valerie Melin da Université de Lille. Ambas exploraram nesta entrevista a temática da juventude segundo suas experiências de pesquisa e intervenção social à luz da abordagem da Pesquisa Biográfica em Educação. 
No escopo das contribuições francesas a esse dossiê, para além da entrevista, Valérie Melin apresenta os resultados de um dispositivo de intervenção voltado para a produção de uma reflexão filosófica acerca da religiosidade, realizado com jovens em curso de retomada dos estudos após uma fase de abandono. Já a professora da Université de Rouen, Anne Dizerbo, apresenta os resultados de sua pesquisa com jovens estudantes do ensino fundamental afim de refletir sobre as formas de subjetivação inscritas no percurso de formação destes jovens. Para fechar esse bloco de contribuições, Geneviève Lalik, doutoranda do Conservatoire National de Arts et Metiers - CNAM, coloca em evidência a importância dos momentos de encontro com o outro no contexto do seu trabalho de pesquisa com jovens adultos que se encontram presos e que passam por uma formação para uma futura inserção profissional. A pesquisadora destaca a importância da alteridade no desenvolvimento de pesquisa de base biográfica.

Entre as contribuições brasileiras, tem-se o trabalho dos pesquisadores Elizeu Clementino de Souza, Nanci Rodrigues Orrico, Hanilton e Ribeiro de Souza (UNEB) que se interessaram pelo contexto das experiências rurais e o rito de passagem entre a escola rural e urbana para compreender os anseios e expectativas em torno das inserções sociais e no mercado de trabalho dos jovens participantes da pesquisa. Para finalizar, as pesquisadoras Juliana Batista dos Reis e Juarez Tarcísio Dayrell (UFMG) apresentam os resultados da pesquisa biográfica realizada com uma jovem negra e moradora de uma favela de Belo Horizonte afim de descrever e compreender como se configuram os processos de socialização e individuação desta jovem.

Assim, o presente dossiê apresenta resultados de estudos nacionais e internacionais que se basearam na abordagem biográfica com vistas a contribuir para aprofundar e ampliar o debate e a reflexão em torno da temática da(s) juventude(s).

\section{APRESENTAÇÃO DOS ARTIGOS DE FLUXO CONTÍNUO}

Os artigos de fluxo contínuo trazem debates sobre aspectos educacionais, enfocando juventudes, tecnologias digitais, prática docente, competência profissional, desigualdade e pesquisas bibliográficas. A discussão dos artigos passa por pesquisas realizadas no Brasil, possibilitando o acesso a diversos referenciais teóricos.

O primeiro artigo da sessão de Artigos é escrito por Máximo Augusto Campos Masson, Maria Teresa Vianna Van Acker e intitulado "Experiências escolares de jovens de classes populares e construções do futuro". O foco é o processo de construção de expectativas profissionais, sendo discutidas relações entre escolarização e visões de futuro 
de jovens. Foram usados observação etnográfica, entrevistas, e questionários, sendo encontradas visões de futuro pelos jovens.

O segundo artigo, de autoria de Manoel Valquer Oliveira Melo, Oriowaldo Queda, Patrick Oliveira Silva, Láudia Frankielle da Silva Nascimento é intitulado "Escola e desenraizamento social: expressões da juventude rural na região do semiárido de Alagoas (Brasil)". Ele apresenta uma pesquisa de extensão realizada em escola do campo, na qual foram aplicados 80 questionários a jovens estudantes. A constatação foi sobre a incipiência das disposições e estratégias para democratizar a educação nas escolas do campo em Alagoas.

O terceiro artigo "Gestaltpedagogia: um caminho trilhado na intersubjetividade", de autoria de Adieliton Tavares Cezar apresenta a proposta educacional da Gestaltpedagogia. Para o delineamento da proposta, o autor discute a dimensão histórica do termo, apontando suas influências, meta e postura. Apresenta, também, que o aluno é o centro do processo de ensino e aprendizagem.

O artigo quarto intitulado "Formação de professores para o uso das TIC nos anos iniciais" de autoria de Fernando Silvio Cavalcante Pimentel e Antonia Eunice de Jesus do Nascimento discute a questão das tecnologias da informação e comunicação na educação, em especial na formação de professores, apontando a necessidade da integração da formação nos cursos tanto de formação inicial quanto continuada.

O quinto artigo é intitulado "A reflexão sobre o design e a resolução de problemas abertos com a utilização das tecnologias digitais: um processo potencializador na formação do educador matemático". As autoras Fabiane Fischer Figueiredo e Claudia Lisete Oliveira Groenwald discutem uma pesquisa em que foram utilizadas as tecnologias digitais a partir do design de problema. Como resultado observou-se que esta abordagem favorece 0 ensino de conhecimentos matemáticos.

O sexto artigo intitulado "Programa Institucional de Bolsas de Iniciação a Docência: análise das publicações do ENPEC", de autoria de Eril Medeiros da Fonseca e Daniela Krause Bierhalz apresenta as publicações sobre o PIBID no período de 2007 a 2015 em um evento específico (ENPEC). Foram elencadas quatro categorias de análise, com destaque para formação de professores e conclui que o programa traz contribuições relevantes par a formação de professores.

O sétimo artigo é intitulado "Desafios de ensino de qualidade: concepções e práticas docentes". Os autores Jean Mac Cole Tavares Santos e Erivelton Nunes DE Almeida partem dos sentidos construídos por professores do ensino básico da cidade de Mossoró$\mathrm{RN}$ acerca do que vem a ser qualidade. Encontram que o termo qualidade envolve 
influências e negociações de sentidos e que esta polissemia contribui para desmistificar a perspectiva de unidade do fenômeno.

O oitavo artigo "Revisão sistemática sobre a publicação científica brasileira na base de dados SciELO sobre pedagogia hospitalar" de autoria de Lúcia Maria Santos Tinós, Sheila Maria Mazer-Gonçalves, Isabella Maria Cruz Fantacini, Gabriella Viccari apresenta levantamento bibliográfico. O foco foi Pedagogia Hospitalar e as autoras concluíram que há poucas publicações sobre o tema na área, sendo importante o incremento destas para maior reconhecimento e investimento para a Pedagogia Hospitalar.

O nono artigo é intitulado "A geração de desigualdades sociais no bojo da escola pública: relações de controle e dominação", de autoria de Carlos Henrique Ferreira Rodrigues enfoca o conceito de desigualdade escolar, a partir da discussão de algumas categorias explicativas, a saber: desigualdade social, dualidade escolar, violência simbólica. A pesquisa qualitativa chegou ao resultado de que a desigualdade é latente na escola e há muitos desafios a serem enfrentados.

O artigo décimo intitulado "Diferentes cenários e representações da competência profissional docente: o caso de professores de matemática brasileiros e franceses" foi escrito por Elisângela Bastos de Melo Espindola, Licia de Souza Leão Maia. A partir do referencial das representações sociais, as autoras apresentam a perspectiva de professores tanto brasileiros quanto franceses no tocante à competência profissional docente e destacam, nos resultados, que as representações estavam centradas em diferentes dimensões: cognitiva, afetivo-motivacional, ético-política e social.

A sessão de resenhas conta com duas resenhas.

A primeira resenha é de autoria de Rosana Cristina Gimael e intitulada "O impacto socioeducacional das tecnologias digitais". É baseado numa coletânea de quinze artigos com o título de "Olhares sobre tecnologias digitais". Com foco em tecnologias e linguagem, a coletânea traz relatos de pesquisa de diferentes regiões do Brasil.

A segunda resenha é escrita por Bruno Silva Leite e intitulada "Na busca de ler para ser em aulas de Química: uma breve apresentação". A obra é da educadora Cristhiane Carneiro Cunha Flôr e enfoca a forma de compreensão da produção de sentidos para a Química a partir da leitura, bem como a relação com diversos tipos de textos (literário, enciclopédicos, de divulgação científica, originais de cientistas etc.).

$\mathrm{Na}$ sessão de Dissertações e Teses, temos a divulgação de dois resumos de dissertações.

A primeira é intitulada "Mediação e Desenvolvimento: contribuições do PIBID no processo de ensino-aprendizagem", de autoria de Flavio Pereira de Jesus. 
A segunda é intitulada "Exergames e Saúde Mental: uma pesquisa-intervenção em um CAPS da cidade de Maceió", de autoria de Adilson Rocha Ferreira.

Convidamos a todos e todas a fazerem uma leitura da revista. 